\title{
Color naming deficits and attention-deficit/hyperactivity disorder: A retinal dopaminergic hypothesis Rosemary Tannock ${ }^{* 1,3}$, Tobias Banaschewski²,3 and David Gold ${ }^{4}$
}

\author{
Address: ${ }^{1}$ The University of Toronto, Toronto, Canada: Brain and Behaviour Research Program, The Hospital for Sick Children, Toronto, Canada, \\ ${ }^{2}$ Child and Adolescent Psychiatry, University of Göttingen, Germany, ${ }^{3}$ Centre for Advanced Study at the Norwegian Academy of Science and Letters \\ 2004-2005, Norway and ${ }^{4}$ The University of Western Ontario, London, Canada \\ Email: Rosemary Tannock* - rosemary.tannock@cas.uio.no; Tobias Banaschewski - tbanasc@gwdg.de; David Gold - dagold@yorku.ca \\ * Corresponding author
}

Published: 27 January 2006

Behavioral and Brain Functions 2006, 2:4 doi:10.1 186/1744-908I-2-4
Received: 02 May 2005

Accepted: 27 January 2006

This article is available from: http://www.behavioralandbrainfunctions.com/content/2/l/4

(C) 2006 Tannock et al; licensee BioMed Central Ltd.

This is an Open Access article distributed under the terms of the Creative Commons Attribution License (http://creativecommons.org/licenses/by/2.0), which permits unrestricted use, distribution, and reproduction in any medium, provided the original work is properly cited.

\begin{abstract}
Background: Individuals with Attention-Deficit/Hyperactive Disorder (ADHD) have unexplained difficulties on tasks requiring speeded processing of colored stimuli. Color vision mechanisms, particularly short-wavelength (blue-yellow) pathways, are highly sensitive to various diseases, toxins and drugs that alter dopaminergic neurotransmission. Thus, slow color processing might reflect subtle impairments in the perceptual encoding stage of stimulus color, which arise from hypodopaminergic functioning.

Presentation of hypotheses: I) Color perception of blue-yellow (but not red-green) stimuli is impaired in ADHD as a result of deficient retinal dopamine; 2 ) Impairments in the blue-yellow color mechanism in ADHD contribute to poor performance on speeded color naming tasks that include a substantial proportion of blue-yellow stimuli; and 3) Methylphenidate increases central dopamine and is also believed to increase retinal dopamine, thereby normalizing blue-yellow color perception, which in turn improves performance on the speeded color naming tasks.

Testing the hypothesis: Requires three approaches, including:I) direct assessment of color perception in individuals with ADHD to determine whether blue-yellow color perception is selectively impaired; 2) determination of relationship between performance on neuropsychological tasks requiring speeded color processing and color perception; and 3) randomized, controlled pharmacological intervention with stimulant medication to examine the effects of enhancing central dopamine on color perception and task performance

Implications of hypothesis: If substantiated, the findings of color perception problems would necessitate a re-consideration of current neuropsychological models of attention-deficit/ hyperactivity disorder, guide psycho-education, academic instruction, and require consideration of stimulus color in many of the widely used neuropsychological tests.
\end{abstract}

\section{Background}

Attention-Deficit/Hyperactivity Disorder (ADHD) is a common and impairing childhood-onset disorder characterized by inattention, hyperactivity, and impulsiveness that affects $3-7 \%$ of school-aged children and tends to persist into adulthood [1]. Converging neuroscience evidence suggests that ADHD is often associated with impaired executive functioning, probably arising from 
widespread alterations of neuronal circuits including the prefrontal cortex, basal ganglia, parietal cortex, anterior cingulate, and cerebellum. Hypodopaminergic neurotransmitter functioning is believed to play a central role in its pathophysiology [2-5]. Although sensory and perceptual abilities have been presumed to be intact in ADHD $[2,4,5]$, recent findings are challenging this earlier assumption. For example, reduced visual perceptual sensitivity has been demonstrated in children with ADHD $[6,7]$. Also, individuals with ADHD exhibit unexplained problems in the speeded processing of colored stimuli [822], and stimulant medication, (a common treatment approach for ADHD) is reported to selectively improve naming speed for colors but not for other types of stimuli $[8,23]$.

To date, there is no adequate explanation to account for either the observed color processing problems in ADHD or their selective amelioration by psychostimulant medication. We propose that the color processing problems may reflect subtle detrimental effects of dopaminergic deficiency in the central nervous system on retinal dopamine, which in turn impedes the efficiency of the short-wavelength (blue-cone) color vision mechanism as well as of other visual functions. Prior to elaborating on this hypothesis, we first review the evidence of problems in color processing associated with ADHD and the existing explanatory accounts. We then outline possible empirical approaches to test this hypothesis, and discuss the theoretical and clinical significance of the hypothesis should it be substantiated.

\section{Color processing problems in ADHD}

Several lines of evidence indicate impaired performance on tasks requiring rapid and/or continuous processing of colored stimuli in ADHD. For example, in a seminal study on rapid automatized naming speed, Denckla [9] described four of the five boys with dyslexia who exhibited slow color naming as being "inattentive", but not "hyperkinetic". Notably, most of the boys' errors were associated with naming the colors blue and yellow, but tests for color blindness revealed no abnormalities [9]. Subsequent studies of rapid naming have found consistently that children and adolescents with ADHD exhibit slower naming speed for colors on the Rapid Automatized Naming Test and Stroop Color Word Test, but typically do not exhibit slower naming of letters, words, or digits $[8,10-22]$. Slower color naming on the Stroop ColorWord Test is sometimes found even in the absence of slower word naming or poor interference control [19]. ADHD is also associated with taking more trials to deduce the first sorting rule on the Wisconsin Card Sorting Task $[13,24]$ : the first rule requires participants to sort according to the color of the stimuli and ignore their shape and number. Moreover, one study demonstrated that the number of trials taken to deduce the first sorting rule was associated with slower Stroop color naming in the ADHD group but not in the control group, suggesting that color processing deficits may underlie performance on both tasks [13]. Furthermore, children with ADHD have been found to respond significantly more slowly (about 200 ms slower) to blue stimulus shapes compared to normal peers, but do not differ in their response time to green stimuli in a visual processing task [22]. Collectively, these findings suggest impairments in color perception and preliminary support for this proposition is provided by a recent study of selective attention to color using eventrelated potentials. The findings indicated that boys with ADHD exhibit an early perceptual deficit in selection of visual stimuli on the basis of color (red versus blue) as well as in later semantic stages of visual selective attention [7].

\section{Current explanations of poor color processing in ADHD}

Currently, two classes of explanation (psychological, neurobiological) are discernible in the literature for the observed problems in rapid processing of colored stimuli in individuals with ADHD. These theoretical accounts are not mutually exclusive, but rather they overlap and reflect perspectives taken from different research approaches and different levels of measurement.

Psychological accounts attribute slow color naming to developmental immaturity. For example, the development of color naming appears to be much more difficult for young children than naming shapes or animals [2527]. Also, whereas the fastest speeds of naming alphanumeric stimuli are reached by the age of 16 , the speed of naming colors and objects continues to improve (i.e., become faster) into mature adulthood [28]. Accordingly, the overall immaturity in development associated with ADHD might exacerbate the normal developmental lag in rapid naming of stimulus colors. An alternative psychological explanation attributes slow color naming to developmental problems in effortful semantic processing, which is typically associated with right hemisphere function [8]. Specifically, naming of colors (as well as naming of natural objects) is thought to require more effortful, perceptual and/or semantic processing than naming letters, digits, or man-made objects [30-34]. For instance, terms such as digits, letters, and shapes refer to categories with sharp, clear, and non-overlapping boundaries, while color terms refer to categories with unclear, variable, and overlapping boundaries. Often, there may be more than one plausible name for a given color and asymmetries likely exist between the candidate names (e.g., they may differ in word frequency), thus giving rise to response competition and necessitating more careful and detailed processing or the need to inhibit the more frequent or salient color name $[6,25]$. A related explanation based on response-competition was also proposed by Brodeur and 
colleagues [22] to account for slower processing of blue stimuli compared to green stimuli. Specifically, this finding was attributed to developmental problems in set shifting from the predominant response to the more common green stimuli than to the non-dominant response to the less frequent blue stimuli. Impairments in semantic processing, set-shifting, and response-competition, have all been implicated in ADHD [7,14,35].

An existing neurobiological account of color processing problems in ADHD associates poor color naming or poor color processing performance to alterations in the underlying neural substrate. For example, slower RAN color naming speed (but not the naming speed for RAN letters, objects or digits) was found to be related to smaller anterior superior white matter volumes (both right and left hemispheres) in ADHD compared to healthy controls [29]. Decreased total white matter volumes in children and adolescents with ADHD, which have been reported in several studies [36-39], suggests delayed or deviant myelination of major fiber tracts such as the corpus callosum, which might have a detrimental impact on the speed of interhemispheric transmission involved in speeded color naming.

Current explanations referring to poor sustained attention, problems in set shifting or semantic processing, or differences in white matter volumes associated with ADHD can not easily account for the dissociation between rapid naming of colored stimuli and rapid naming of letters, digits, or words. Nor can they adequately account for the indications that color processing problems appear to be greater for yellow and blue stimuli. Moreover, from a developmental perspective, the neurodevelopmental immaturity hypothesis would predict greater problems in rapid color naming in children with ADHD compared to adolescents, with possible attenuation of the deficits in adults with ADHD. To date this hypothesis has not been tested directly, but meta-analyses of cognitive deficits in children, adolescents, and young adults with ADHD indicate color naming deficits of moderate to large effect size $(\mathrm{d}=.58-.62)$ across the life span with no evidence of agerelated changes $[19,40]$.

\section{Presentation of the hypothesis}

Color perception is controlled, at least in part, by retinal dopaminergic neurons [41]. We propose that slowed color processing and color naming in ADHD reflects a specific problem in blue-yellow color perception, which arises from hypo-functioning retinal dopaminergic mechanisms. In the absence of any evidence to the contrary, changes in central and retinal dopamine are believed to occur together. Thus, hypofunctioning of the central dopaminergic system associated with ADHD [4] will be accompanied by hypo-functioning retinal dopamine. The abnormalities in retinal dopaminergic tone will give rise to subtle, but detrimental effects on the on several aspects of visual function, particularly on the short-wavelength chromatic pathway that is responsible for blue-yellow color perception. Normalization of central dopaminergic functioning via pharmacological intervention with psychostimulant medication will normalize retinal dopamine, which in turn will normalize blue-yellow color perception and performance on tasks requiring speeded color naming.

To present the detailed hypothesis, we first provide the necessary background on color perception and the role of retinal dopamine, then argue how hypo-dopaminergic functioning in ADHD will give rise to impairments in the tritan color mechanism, which in turn will influence speeded color naming on tasks involving a substantial proportion of blue and yellow stimuli.

\section{Color perception and the role of retinal dopamine}

Color perception is based on the three cone photoreceptor types maximally sensitive to long, middle, and short wavelengths in the perceived light spectrum that constitute two functionally and anatomically distinct systems at the retina and lateral geniculate nucleus; a 'red-green' system with a foveal specialization in which long and middle wavelength cone signals are antagonistic, and a 'blue-yellow' pathway in which short wavelength cones are opposed by a combined signals from long and middle wavelength cones without such a foveal overrepresentation [42]. Normal development of the blue-yellow (tri$\tan )$ color mechanism appears to lag behind that of the red-green mechanism, which is functional in human infants by 2 months of age [43-46].

Most color perception defects (i.e., dyschromatopsias or 'color blindness') are congenital and arise from altered sensitivity defects of the $\mathrm{L}$ and $\mathrm{M}$ cones. By contrast to these red-green color vision deficits, which respectively affect $2 \%$ and $6 \%$ of the male population, congenital defects in S-cone sensitivity are rare (about $0.01 \%$ ) but affect both sexes equally [47]. Acquired dyschromatopsias arising from exposure to environmental pollutants [48] usually impair blue-yellow color discrimination. For example, pronounced effects on color perception, often dose-dependent and involving the short-wavelength (blue-yellow) mechanism, are reported following both acute and chronic exposure to organic solvents and elemental mercury $[49,50]$. Moreover, occupational exposure to organic solvents during pregnancy is associated with increased risk of color vision and acuity impairment in the offspring $[51,52]$.

Color perception problems, particularly involving the blue-yellow (tritan) mechanism, have also been linked 
with alterations in retinal dopamine: dopamine is a major neurotransmitter in the mammalian retina $[41,53]$. Dopamine receptors, DRD1 and DRD4 that seems to be associated with a subsensitive postsynaptic receptor if coded by the 7-repeat allele [54] are both found in the retina [53-55]. Retinal dopaminergic neurons are involved in controlling the coupling of horizontal and amacrine cell lateral systems, the organization of the ganglion cell and the bipolar cell receptive fields and modulation of the physiological activity of photoreceptors. Thus, the retinal dopamine system influences light adaptation as well as other visual functions, including color perception, contrast sensitivity, and spatial and temporal processing $[41,53]$. The hypothesis proposed focuses on the role of retinal dopamine in color perception.

Alterations in the level of retinal dopamine are reflected particularly in deficits in the short-wavelength chromatic pathway that is responsible for blue-yellow color discrimination, a system that appears to be especially vulnerable to the effects of disorders and drugs $[41,50,56-58]$. For example, discrimination along the blue-yellow axis (compared to the red-green axis) is particularly impaired in various disorders involving altered dopaminergic mechanisms. Thus, specific blue-yellow color vision disturbances are found in Tourette Syndrome [59], Parkinson's disease [60-63], and Huntington's disease [64]. Changes of retinal dopamine levels arising from cocainewithdrawal [65-67] and normal aging $[41,68]$ have also been associated with blue-yellow color vision losses.

The fundamental mechanisms causing a specific retinal impairment of color discrimination along the blue/yellow axis in dopaminergic disorders and acquired dyschromatopsias remain unclear. Short wavelength sensitive cones may be more fragile than long and medium wavelength sensitive cones or their relative scarcity and anatomical distribution may be responsible for the greater vulnerability of the blue-yellow perception by alterations of the dopaminergic system $[41,47,53,69]$. Accordingly, abnormalities in dopamine production, transport, uptake, or receptor sensitivity could result in impairments in visual processing including color - particularly the color blue. Moreover a selective impairment of the blue-yellow vision system suggests a retinal location of the disturbance rather than a central one $[41,47]$.

\section{Hypo-dopaminergic functioning in ADHD influences color perception}

Hypo-dopaminergic functioning has been postulated in ADHD $[4,70]$ and abnormal levels and density of the dopamine transporter in the brain have been reported in adults with ADHD [71]. Moreover, ADHD has been associated with anomalous alleles of the D1 and DRD4 receptors [72-74]. Thus, dopaminergically-related impairments in visual functioning, and particularly in blue-yellow color perception, are plausible in ADHD.

We propose that the observed impairments in individuals with ADHD on tasks requiring speeded color processing of blue-yellow stimuli might be attributable in part to hypo-functioning of both central and retinal dopamine. Critical to this hypothesis is the premise that alterations in central and retinal dopamine occur in parallel (and that pharmacologically-induced increases in central dopamine also increases retinal dopamine). To our knowledge there is no direct evidence that this is the case. Rather, we draw inferences from the following evidence: 1) cerebrospinal concentrations of a metabolite of CNS dopamine, homovanillic acid, correlates positively with electroretinogram blue-cone amplitude [67]; 2) in Parkinson's disease, death of dopaminergic neurons in the CNS also extend to the retina, resulting in impaired visual functions including blue-yellow color perception [61-63]; 3) the visual deficits in Parkinson's disease are mostly reversed by treatment with the dopamine precursor L-DOPA [41]; 4) methylphenidate, which is the primary treatment modality for ADHD, blocks the re-uptake mechanism of the dopamine transporter, increasing the amount of extracellular dopamine able to bind to its receptors [75]. Thus, changes in the dopamine system, regardless of whether brought about experimentally (lesions, pharmacologically) or naturally (as in ageing or in clinical conditions), leads to predictable changes in retinal function $[41,53]$.

According to this retinal dopaminergic hypothesis, deficits in blue-yellow color perception result in poor performance on many of the standard neuropsychological tasks (e.g., Stroop, RAN, Wisconsin Card Sorting Task) that include a substantial proportion of blue-yellow stimuli. Thus poor task performance may reflect subtle impairments in color vision as well as, or instead of, impairments in higher-order cognitive function. Consistent with this prediction are the recent findings that individual differences in color perception influence performance on the classic Stroop color-word task and that incongruent opponent color pairs (e.g., the word $B L U E$ in yellow ink) decrease the strength of Stroop interference compared to non-opponent color pairs (e.g., $B L U E$ in red ink) [76]. A neural network simulation of the data confirmed that the difference in magnitude of Stroop interference between incongruent color-word pairs involving opponent versus nonopponent colors was attributable to sensory processing of the physical color of the stimuli (particularly the color yellow), which occurs at the level of retinal ganglion cells [76]. Also, it has been demonstrated that visual function deficiencies associated with normal aging (reduced acuity, contrast sensitivity, and color weakness) accounted for a substantial amount of the variance in Stroop performance [77]. The preceding 
findings suggest that impairments in the early perceptualencoding stage of stimulus color contribute to slow performance on neuropsychological tasks requiring speeded naming of color, as well as conceptual and attentional factors [76].

Stimulant-induced increases in the availability of dopamine would be expected to be reflected in retinal dopaminergic tone and thus have therapeutic effects on the short-wavelength mechanism. Thus, methylphenidate would be expected to improve visual functioning, including the speed of color processing and naming. Indeed, there is preliminary evidence of beneficial effects of methylphenidate on color naming in children with ADHD $[8,23]$.

\section{Gender effects}

Alterations in short-wavelengths mechanism may be gender-related. Notably, estrogen has been found to have a modulatory influence on dopamine activity [78] and a few studies have revealed significant variations in dopaminergic tone and dopamine receptor density that are sex-specific $[79,80]$. Correspondingly, gender-related differences observed in visual-cortical fMRI BOLD response to blue light (higher BOLD signal change in males), but not to red light, have been reported that may be related to variations in dopamine function and/or the effects of estrogen on dopamine [81]. Furthermore, visual pattern reversal evoked potentials have been found to vary with menstrual phase in females and display faster conduction times during the period of peak estrogen levels [82]. Given the incidence of ADHD is estimated to be three times greater in males than females, the relationship between estrogen and dopamine may provide an important area for further investigation.

\section{Developmental effects}

The limited data available on developmental changes in retinal and central dopaminergic mechanisms, color perception, and color naming, suggest that the retinal dopamine hypothesis will likely hold for children, adolescents, and adults with ADHD. For example, animal research indicates that dopaminergic neurons are among the first neurochemical systems to appear in the developing retina and that the neural retina and dopaminergic system interact closely in a two-way manner throughout developmental period [53]. It is only as the animal passes through maturity towards senescence that the number of retinal dopamine neurons decrease [53]. Thus, assuming that hyperdopaminergic function in ADHD occurs early in pre- or post-natal life, parallel hypofunctioning of the retinal dopamine system is expected to have a detrimental effect on the development of blue-yellow color vision and these early deficits are likely to persist.
On the other hand, the increasing efficiency of the mature (adult) brain permits the development and use of compensatory strategies. Thus, adults with ADHD, although impaired in color perception relative to healthy peers, may be able to call upon compensatory attentional strategies to enhance performance on tasks requiring rapid perception of blue and yellow stimuli, thereby exhibiting better performance than children or adolescents with ADHD.

\section{Testing the hypothesis}

Three strategies are proposed to provide a rigorous test of the hypothesis: 1) direct assessment of color vision pathways in individuals with ADHD versus a comparison group of healthy peers; 2) evaluation of the relationship between color vision (particularly for blue-yellow stimuli) and performance on tasks requiring speeded color processing; and 3) investigation of stimulant effects on both color vision and performance on those tasks in individuals with ADHD. Color vision can be assessed directly using clinical measures that are sensitive to problems with stimuli along the blue-yellow axis [83-85] as well as using color visual evoked potential (VEP), which is an objective, sensitive, and non-invasive measure of neuronal integrity of red-green and blue-yellow pathways [86-88]. A detailed neuro-opthalmological examination is also required to rule out confounding factors, such as problems with visual acuity, refraction, contrast sensitivity, or structure of the fundus (ocular media, posterior pole, and macular area of the retina). Evidence of selective impairments in blue-yellow but not red-green color perception would mitigate an alternative explanation that impaired perception of stimulus color reflects an attention dysfunction, and be consistent with the proposed hypothesis that dysregulation of central and retinal dopamine impairs blueyellow color perception. Next, regression techniques are required to examine the relationship between performance on various standardized neuropsychological tests requiring speeded color processing [30,31,89] and the color vision measures (e.g., VEP latencies, continuous scores from clinical color vision tests). Finally, a randomized, double-blind, placebo-controlled, within-subject design is required to test whether stimulant-induced increases in central dopamine also produces parallel increases in retinal dopamine, as indexed by improved performance on both color vision and speeded color naming.

\section{Theoretical and Clinical Implications of the Hypothesis}

Convergent findings from empirical investigations and neural network simulation support the hypothesis that color perception contributes to performance on neuropsychological tasks requiring speeded color naming [70,71]. Preliminary support for our hypothesis that color percep- 
tion of blue-yellow (but not red-green) stimuli is impaired in ADHD as a result of deficient central and retinal dopamine is provided by findings from our recent small-scaled study that demonstrated selective impairments in blue-yellow (i.e, not red-green) color perception in children with ADHD [83]. Also, the contrasting effects of dopaminergic and noradrenergic drugs on color naming in individuals with ADHD $[8,23,91]$ are consistent with the premise that increases in central dopamine will also increase retinal dopamine, resulting in improved color processing and naming.

If substantiated in larger well-controlled studies, evidence that blue-yellow color perception problems contribute to poor performance on neuropsychological tasks of executive function requiring speeded color processing, would necessitate careful consideration to stimulus color when interpreting performance on many of the standard neuropsychological tests. Also, evidence of specific impairments in blue-yellow color perception (and other visual functions) would necessitate a reconsideration of current neuropsychological models of ADHD, which posit the core deficits to be in higher-order executive functioning and not at the level of sensory and perceptual processing. From a clinical perspective, this retinal-dopaminergic hypothesis might indicate the need to include a visual examination in the assessment of ADHD, and raises the possibility that electroretinogram blue cone amplitudes may also be a possible neurobiologic marker related to central dopamine function in ADHD, as well as in cocaine-dependent patients [67].

\section{List of Abbreviations}

ADHD: Attention-Deficit/Hyperactivity Disorder

RAN: Rapid Automatized Naming Test

VEP: Visual evoked potential

\section{Competing interests}

The author(s) declare that they have no competing interests.

\section{Authors' contributions}

RT developed the hypothesis and prepared the initial draft of the manuscript; TB refined it and conducted a preliminary test of it; DG conducted an in-depth literature search. All authors helped revising the manuscript and have read and approved the final manuscript.

\section{Acknowledgements}

This article is part of the international and interdisciplinary project "ADHD: From genes to therapy" (Project leader: Terje Sagvolden) conducted at the Centre for Advanced Study (CAS) in Oslo, Norway (2004-2005), in which R. Tannock and T. Banaschewski were participants. This work was also supported in part by an operating grant from the US National Institutes of
Health (RT) and a Summer Student Fellowship (D. Gold) from the Canadian Language and Literacy Research Network. The authors thank Anne-Claude V. Bedard, Rhonda Martinussen, and Maggie Toplak for their helpful comments.

\section{References}

I. American Psychiatric Association: Diagnostic and statistical manual of mental disorders, Text Revision (DSM-IV-TR) 4th edition. Washington, DC: American Psychiatric Association; 2000.

2. Banaschewski T, Hollis C, Oosterlaan J, Roeyers H, Rubia K, Willcutt $E$, Taylor $E$ : Towards an understanding of unique and shared pathways in the psychopathophysiology of AD/HD. Dev Sci 2005, 8: $132-140$.

3. Castellanos FX, Tannock R: Neuroscience of attention-deficit/ hyperactivity disorder : the search for endophenotypes. Nat Rev Neurosci 2002, 3:617-628.

4. Sagvolden T, Johansen EB, Aase H, Russell V: A dynamic developmental theory of attention-deficit/hyperactivity disorder (ADHD) predominantly hyperactive/impulsive and combined subtypes. Behav Brain Sci 2005, 28:397-468.

5. Taylor E, Döpfner M, Sergeant J, Asherson P, Banaschewski T, Buitelaar J, Coghill D, Dankaerts M, Rothenberger A, Sonuga-Barke E, Steinhausen HC, Zuddas A: European clinical guidelines for hyperkinetic disorder - first upgrade. Eur Child Adolesc Psychiatry 2004, I 3(Suppl I):S7-S30.

6. Jonkman LM, Kenemans JL, Kemner C, Verbaten MN, van Engeland H: Dipole source localization of event-related brain activity indicative of an early visual selective attention deficit in ADHD children. Clin Neurophysiol 2004, 15:1537-1549.

7. Van der Stelt O, van der Molen M, Boudewijn Gunning W, Kok A: Neuroelectrical signs of selective attention to color in boys with attention-deficit hyperactivity disorder. Cognitive Brain Research 200I, 1 2:245-264.

8. Tannock R, Martinussen R, Frijters J: Naming speed performance and stimulant effects indicate effortful, semantic processing deficits in attention-deficit/hyperactivity disorder. J Abnorm Child Psychol 2000, 28:237-252.

9. Denckla MB: Color-naming defects in dyslexic boys. Cortex 1972, 8: |64-176.

10. Brock SE, Knapp PK: Reading comprehension abilities of children with Attention-Deficit/Hyperactivity Disorder. Journal of Attention Disorders 1996, I: 173-185.

II. Carte ET, Nigg JT, Hinshaw SP: Neuropsychological functioning, motor speed, and language processing in boys with and without ADHD. J Abnorm Child Psychol 1996, 24:48I-498.

12. Houghton S, Douglas G, West J, Whiting K, Wall M, Langsford S, et al.: Differential patterns of executive function in children with attention-deficit hyperactivity disorder according to gender and subtype. J Child Neurol 1999, 1 4:80I-805.

13. Lawrence V, Houghton S, Douglas G, Durkin K, Whiting K, Tannock R: Executive function and ADHD: a comparison of children's performance during neuropsychological testing and realworld activities. J Attention Disorders 2004, 7:137-149.

14. Mclnnes A, Humphries T, Hogg-Johnson S, Tannock R: Listening comprehension and working memory are impaired in attention-deficit hyperactivity disorder irrespective of language impairment. J Abnorm Child Psychol 2003, 3 I:427-443.

15. Nigg JT, Hinshaw SP, Carte ET, Treuting JJ: Neuropsychological correlates of childhood attention-deficit/hyperactivity disorder: explainable by comorbid disruptive behavior or reading problems? J Abnorm Psychol 1998, I 07:468-480.

16. Rucklidge JJ, Tannock R: Neuropsychological profiles of adolescents with ADHD: effects of reading difficulties and gender. J Child Psychol Psychiatry 2002, 43:988-1003.

17. Schuerholz LJ, Harris EL, Baumgardner TL, Reiss AL, Freund LS, Church RP, et al: An analysis of two discrepancy-based models and a processing- deficit approach in identifying learning disabilities. J Learn Disabilities 1995, 28:18-29.

18. Semrud-Clikeman M, Guy K, Griffin JD, Hynd GW: Rapid naming deficits in children and adolescents with reading disabilities and attention deficit hyperactivity disorder. Brain Lang 2000, 74:70-83.

19. van Mourik R, Oosterlaan J, Sergeant JA: The Stroop revisited: a meta-analysis of interference control in AD/HD. J Child Psychol Psychiatry 2005, 46:150-165. 
20. Willcutt EG, Pennington BF, Boada R, Ogline JS, Tunick RA, Chhabildas NA, Olson RK: A comparison of the cognitive deficits in reading disability and attention-deficit/hyperactivity disorder. J Abnorm Psycho 200I, I I0:157-I72.

21. Willcutt EG, Pennington BF, Olson RK, Chhabildas N, Hulslander J: Neuropsychological analyses of comorbidity between reading disability and attention deficit hyperactivity disorder: in search of the common deficit. Dev Neuropsychol 2005, 27:35-78.

22. Brodeur D, Andrade B: Attentional control and children with ADHD. Canadian Psychology 2002, 43:1 I 3 [http://www.cpa/vancou ver/Saturday.pdf]. (accessed April 20 2005) Presentation at 63rd annual conference Canadian Psychological Association, Vancouver, B.C, May 30-June 2, 2002.

23. Bedard AC, Ickowicz A, Tannock R: Methylphenidate improves stroop naming speed, but not response interference, in children with Attention-Deficit/Hyperactivity Disorder. J Child Adolesc Psychiatry 2002, I 2:301-309.

24. Grodzinsky GM, Diamond R: Frontal lobe functioning in boys with attention-deficit/hyperactivity disorder. Dev Neuropsychol 1992, 8:427-445

25. Bornstein $\mathrm{MH}$ : On the development of color naming in young children: data and theory. Brain Lang 1985, 26:72-93.

26. Braisby N, Dockrell J: Why is color naming difficult? J Child Lang 1999, 26:23-47.

27. Soja NN: Young children's concept of color and its relation to the acquisition of color words. Child Dev 1994, 65:9|8-937.

28. Van den Bos KP, Ziljstra BJH, Spelberg HC: Life span data on continuous-naming speeds of number, letters, colors, and pictured objects, and word-reading speed. Scientific Studies of Reading 2002, 6:25-49.

29. Semrud-Clikeman M, Steingard RJ, Filipek P, Biederman J, Bekken K, Renshaw PF: Using MRI to examine brain-behavior relationships in males with attention deficit disorder with hyperactivity. J Am Acad Child Adolesc Psychiatry 2000, 39:477-484.

30. Denkla MB, Rudel R: Rapid "automatized" naming of pictured objects, colors, letters, and numbers by normal children. Cortex 1974, 10: 186-202.

3I. Denkla MB, Rudel R: Rapid "automatized" naming (R.A.N.): dyslexia differentiated from other learning disabilities. Neuropsychologia 1976, 14:47|-479.

32. Gerlach C, Law I, Gade A, Paulson OB: Perceptual differentiation and category effects in normal object recognition: a PET study. Brain 1999, I 22(Pt I I):2159-2 I70.

33. Moore CJ, Price CJ: A functional neuroimaging study of the variables that generate category-specific object processing differences. Brain 1999, 122:943-962.

34. Wolf M: Naming speed and reading: The contribution of the cognitive neurosciences. Reading Research Quarterly |991, 26:23-|4I.

35. Renz K, Lorch EP, Milich R, Lemberger C, Bodner A, Welsh R: Online story representation in boys with attention deficit hyperactivity disorder. J Abnorm Child Psychol 2003, 3 1:93-104.

36. Castellanos FX, Lee PP, Sharp W, Jeffries NO, Greenstein DK, Clasen LS, Blumenthal JD, James RS, Ebens CL, Walter JM, Zijdenbos A, Evans AC, Giedd JN, Rapoport JL: Developmental trajectories of brain volume abnormalities in children and adolescents with attention-deficit/hyperactivity disorder. JAMA 288: 1740-1748.

37. Durston S, Hulshoff Pol HE, Schnack HG, Buitelaar JK, Steenhuis MP, Minderaa RB, Kahn RS, van Engeland $\mathrm{H}$ : Magnetic resonance imaging of boys with attention-deficit/hyperactivity disorder and their unaffected siblings. J Am Acad Child Adolesc Psychiatry 2004, 43:332-340.

38. Mostofsky SH, Cooper KL, Kates WR, Denckla MB, Kauffman WE: Smaller prefrontal and premotor volumes in boys with attention-deficit/hyperactivity disorder. Biol Psychiatry 2002, 52:785-794.

39. Overmeyer S, Bullmore ET, Suckling J, Simmons A, Williams SC, Santosh PJ, Taylor E: Distributed grey and white matter deficits in hyperkinetic disorder MRI evidence for anatomical abnormality in an attentional network. Psychol Med 31: | 425-1435.

40. Boonstra AM, Oosterlaan J, Sergeant JA, Buitelaar JK: Executive functioning in adult ADHD: a meta-analytic review. Psychol Med 2005, 35: 1097-1 I08.

41. Djamgoz MBA, Hankins MW, Hirano J, Archer SN: Neurobiology of retinal dopamine in relation to degenerative states of the tis- sue. Vision Research. Special Issue: Vision and Neurodegenerative Diseases 1997, 37:3509-3529.

42. Mullen KT, Kingdom FA: Differential distributions of red-green and blue-yellow cone opponency across the visual field. Vis Neurosci 2002, 19:109-118.

43. Crognale MA: Development, maturation, and aging of chromatic visual pathways: VEP results. J Vis 2002, 2:438-450.

44. Peeples DR, Teller DY: White-adapted photopic spectral sensitivity in human infants. Vision Res 1978, 18:49-53.

45. Suttle CM, Banks MS, Graf EW: FPL and sweep VEP to tritan stimuli in young human infants. Vision Res 2002, 42:2879-2891.

46. Teller DY, Brooks TE, Palmer J: Infant color vision: moving tritan stimuli do not elicit directionally appropriate eye movements in 2- and 4-month-olds. Vision Res 1997, 37:899-9। I.

47. Hart WM: Acquired dyschromatopsias. Surv Ophthalmol 1987, 32: $|0-3|$.

48. Gobba F, Cavalleri A: Color vision impairment in workers exposed to neurotoxic chemicals. Neurotoxicology 2003 24:693-702.

49. Iregren A, Andersson M, Nylen P: Color vision and occupational chemical exposures: I. An overview of tests and effects. Neurotoxicology 2002, 23:719-733.

50. Sharanjeet-Kaur, Mursyid A, Kamaruddin A, Ariffin A: Effect of petroleum derivatives and solvents on color perception. Clin Exp Optom 2004, 87:339-343.

5I. Till C, Westall CA, Rovet JF, Koren G: Effects of maternal occupational exposure to organic solvents on offspring visual functioning: A prospective controlled study. Teratology 200I, 64:|34-|4|.

52. Till C, Rovet J, Koren G, Westall CA: Assessment of Visual Functions Following Prenatal Exposure to Organic Solvents. Neurotoxicology 2003, 24:725-73I.

53. Witkovsky P: Dopamine and retinal function. Doc Ophthalmol 2004, 108: 17-40

54. Asghari V, Sanyal S, Buchwaldt S, Paterson A, Jovanovic V, Van Tol $\mathrm{HH}$ : Modulation of intracellular cyclic AMP levels by different human dopamine D4 receptor variants. I Neurochem 1995, 65: II57-II65.

55. Missale C, Nash SR, Robinson SW, Jaber M, Caron MG: Dopamine receptors: from structure to function. Physiol Rev 1998, 78:189-225

56. Hood DC, Benimoff NI, Greenstein VC: The response range of the blue-cone pathways: a source of vulnerability to disease. Invest Ophthalmol Vis Sci 1984, 25:864-867.

57. Sperling HG: Vulnerability of the blue-sensitive mechanism. In Retinal and visual dysfunction: Inherited and acquired color deficiencies Volume 7. Boca Raton, FL: CRC Press; 1991:72-87.

58. Yammamoto S, Kamiyama M, Nitta K, Yamada T, Hayasaka S: Selective reduction of the $S$ cone electroretinogram in diabetes. $\mathrm{Br}$ J Ophthalmol 1996, 80:973-875.

59. Melun JP, Morin LM, Muise JG, DesRosiers M: Color vision abnormalities in Gilles de la Tourette Syndrome. J Neurological Sciences 2001, 186: 107-II0.

60. Buttner T, Kuhn W, Muller T, Patzold T, Heidbrink K, Przuntek H: Distorted color discrimination in 'de novo' parkinsonian patients. Neurology 1995, 45:386-387.

61. Haug BA, Kolle RU, Trenkwalder C, Oertel WH, Paulus W: Predominant affection of the blue cone pathway in Parkinson's disease. Brain 1995, I I 8:77|-778.

62. Pieri V, Diederich NJ, Raman R, Goetz CG: Decreased color discrimination and contrast sensitivity in Parkinson's disease. $J$ Neurol Sci 2000, I72:7-II.

63. Sartucci F, Orlandi G, Lucetti C, Bonuccelli U, Murri L, Orsini C, Porciatti $\mathrm{V}$ : Changes in pattern electroretinograms to equiluminant red-green and blue-yellow gratings in patients with early Parkinson's disease. J Clin Neurophysiol 2003, 20:375-38I.

64. Paulus W, Schwarz G, Werner A, Lange H, Bayer A, Hofschuster M, Muller N, Zrenner E: Impairment of retinal increment thresholds in Huntington's disease. Ann Neuro 1993, 34:574-578.

65. Desai P, Roy M, Roy A, Brown S, Smelson D: Impaired color vision in cocaine withdrawal patients. Arch Gen Psychiatry 1997, 54:696-699.

66. Roy M, Roy A, Williams J, Weinberger L, Smelson D: Reduced blue cone electroretinogram in cocaine-withdrawn patients. Arch Gen Psychiatry 1997, 54:153-156. 
67. Roy A, Roy M, Berman J, Gonzalez B: Blue cone electroretinogram amplitudes are related to dopamine function in cocaine-dependent patients. Psychiatry Research 2003, I I 7:191-195.

68. Bannon MJ, Poosch MS, Xia Y, Goebel DJ, Cassin B, Kapatos G: Dopamine transporter mRNA content in human substantia nigra decreases precipitously with age. PNAS 1992, 89:7095-7099.

69. Masson G, Mestre D, Blin O: Dopaminergic modulation of visual sensitivity in man. Fundam Clin Pharmaco 1993, 7:449-463.

70. Solanto MV: Neuropsychopharmological mechanisms of stimulant drug action in attention-deficit hyperactivity disorder: a review and integration. Behav Brain Res 1998, 94:127-I52.

7I. Madras B, Miller G, Fischman A: The dopamine transporter: relevance to attention deficit hyperactivity disorder. Behav Brain Res 2002, 130:57-63.

72. Misener VL, Luca P, Azeke O, Crosbie J, Waldman I, Tannock R, Roberts W, Malone M, Schachar R, Ickowicz A, Kennedy JL, Barr CL: Linkage of the dopamine receptor $D I$ gene to attention-deficit/hyperactivity disorder. Mol Psychiatry 2004, 9:500-509.

73. Bobb AJ, Addington AM, Sidransky E, Gornick MC, Lerch JP, Greenstein DK, Clasen LS, Sharp WS, Inoff-Germain G, Wavrant-De Vrieze F, Arcos-Burgos M, Straub RE, Hardy JA, Castellanos FX, Rapoport JL: Support for association between ADHD and two candidate genes: NET I and DRD I. Am J Med Genet B Neuropsychiatr Genet 2005, I 34:67-72.

74. Faraone SV, Doyle AE, Mick E, Biederman J: Meta-analysis of the association between the 7-repeat allele of the dopamine $D(4)$ receptor gene and attention deficit hyperactivity disorder. Am J Psychiatr 200I, I 58:1052-1057.

75. Volkow ND, Chang L, Wang G], Fowler JS, Franceschi D, Sedler M, Gatley SJ, Miller E, Hitzemann R, Ding YS, Logan J: Loss of dopamine transporters in methamphetamine abusers recovers with protracted abstinence. I Neurosci 200I, 21:9414-9418

76. Laeng B, Lag T, Brennen T: Reduced Stroop interference for opponent colors may be due to input factors: evidence from individual differences and a neural network simulation. J Exp Psychol Hum Percept Perform 2005, 3 I:438-452.

77. Van Boxtel MPJ, ten Tusscher MPM, Metsemakers JFM, Willems B, Jolles J: Visual determinants of reduced performance on the Stroop Color-Word Test in normal aging individuals. I Clin Exp Neuropsychol 200I, 23:620-627.

78. Lindamer LA, Lohr JB, Harris MJ, Jeste DV: Gender, estrogen, and schizophrenia. Psychopharm Bull 1997, 33:221-228.

79. Andersen SL, Teicher $\mathrm{MH}$ : Sex differences in dopamine receptors and their relevance to ADHD. Neurosci Biobehav Reviews 2000, 24:|37-|4|.

80. Walker QD, Rooney MB, Wightman RM, Kuhn CM: Dopamine release and uptake are greater in female than male rat striatum as measured by fast cyclic voltammetry. Neuroscience 2000, 95:1061-1975.

81. Cowan RL, Frederick BB, Rainey M, Levin JM, Maas LC, Bang J, et al.: Sex differences in response to red and blue light in human primary visual cortex: a bold fMRI study. Psychiatry Res 2000, 100:129-138.

82. Yilmaz $\mathrm{H}$, Erkin EF, Mavioglu $\mathrm{H}$, Sungurtekin $\mathrm{U}$ : Changes in pattern reversal evoked potentials during menstrual cycle. Int Ophthalmol 1998, 22:27-30.

83. Birch J: Clinical use of the American Optical Company (Hardy, Rand and Rittler) pseudoisochromatic plates for red-green color deficiency. Ophthalmic Physiol Opt 1997, I 7:248-254.

84. Mollon JD, Reffin JP: Manual for the Mollon-Reffin Minimalist Test, Version 0.7 Cambridge: Department of Experimental Psychology; 1994.

85. Farnsworth D: The Farnsworth Munsell 100-Hue dichotomous tests for color vision. J Opt Soc Am 1943, 33:568-576.

86. Suttle C, Harding GFA: Morphology of transient VEPs to Luminance and Chromatic pattern Onset and Offset. Vision Research 1999, 39:I577-I584.

87. Suttle CM, Banks MS, Graf EW: FPL and sweep VEP to tritan stimuli in young human infants. Vision Res 2002, 42:2879-289I.

88. Till C, Rovet JF, Koren G, Westall CA: Assessment of visual functions following prenatal exposure to organic solvents. Neurotoxicology 2003, 24:725-73I.
89. Golden C): Stroop Color Word Test: A manual for clinical and experimental uses Wood Dale, Illinois: Stoelting Company; 1978.

90. Banaschewski T, Ruppert S, Tannock R, Albrecht B, Becker A, Uebel $H$, Sergeant JA, Rothenberger A: Color perception in ADHD. J Child Adolesc Psychol Psychiat 2005. [epub online publication date: Sep 25, 2005.]

91. Spencer T, Biederman J, Wilens T, Prince J, Hatch M, Jones J, Harding M, Faraone SV, Seidman L: Effectiveness and tolerability of tomoxetine in adults with attention deficit hyperactivity disorder. Am J Psychiatry 1998, 1 55:693-695.
Publish with Biomed Central and every scientist can read your work free of charge

"BioMed Central will be the most significant development for disseminating the results of biomedical research in our lifetime. "

Sir Paul Nurse, Cancer Research UK

Your research papers will be:

- available free of charge to the entire biomedical community

- peer reviewed and published immediately upon acceptance

- cited in PubMed and archived on PubMed Central

- yours - you keep the copyright

Submit your manuscript here:

http://www.biomedcentral.com/info/publishing_adv.asp
BioMedcentral 